of neoplasms and the meaning of pathological terms. Thus, "restorative hyperplasia" is regarded as a better term than "regeneration," and "nodular hyperplasia" is preferred to "regeneration nodules." A particularly important recommendation is that, in relation to liver cancer in man, priority should now be given to assessing the role of known or suspected hepatocarcinogens rather than to increasing the already bewilderingly large number of liver carcinogens listed during the conference by G. P. Warwick. ${ }^{1}$

1 World Health Organization, International Agency for Research on Cancer, Liver Cancer: Proceedings of a Working Conference Lyon 1972. In press. Andervont, H. B., and Dunn, T. B., Fournal of the National Cancer Institute, 1952, 13, 455.

s Andervont, H. B., Grady, H. G., and Edwards, J. E., Fournal of the National Cancer Institute, 1942, 3, 131.

4 Lemon, P. G., in Pathology of Laboratory Rats and Mice, ed. E. Cotchin and F. J. C. Roe, p. 25. Oxford, Blackwell Scientific Publications, 1967. ${ }^{3}$ Roe, F. J. C., et al., fournal of the National Cancer Institute, 1971, 47, 593.

- Andervont, H. B., fournal of the National Cancer Institute, 1951, 11, 581.

7 Agnew, L. R. C., and Gardner, W. U., Cancer Research, 1952, 12, 757

8 Innes, J. R. M., et al., Fournal of the National Cancer Institute, 1969, 42, 1101 .

- Stewart, H. L., and Snell, K. C., Acta: Unio Internationalis Contra Cancrum, 1957, 13, 770.

10 Higginson, J., Cancer Research, 1963, 23, 1624

11 Prince, A. M., Proceedings of the National Academy of Sciences of the United States of America, 1968, 60, 814.

12 Levene, C., and Blumberg, B. S., Nature, 1969, 221, 195.

18 Abelev, G. I., Progress in Experimental Tumor Research, 1965, 7, 104.

14 Uriel, J., Pathologie et Biologie, 1969, 17, 877.

\section{Generalized Pustular Psoriasis}

Psoriasis, one of the great silent diseases of mankind, occasionally erupts with violence to produce a dangerous erythroderma, a crippling arthritis, or death from a horrible pustulation of the skin surface. T. J. Ryan and H. Baker ${ }^{1}$ recently reviewed the prognosis of generalized pustular psoriasis. They had information on 155 patients, and in 106 followed up over several years they concluded that death was due to the disease or its treatment in 26 a shocking figure. From further analysis they concluded that the type of pustular psoriasis which often starts around the nail-folds in adult life has a bad prognosis and that the disease is often caused by therapy, since generalized pustular psoriasis is often associated with systemic corticosteroid and methotrexate treatment.

This association, as Ryan and Baker had earlier realized, might simply mean that the more severely ill patients require more treatment, and many think this the most likely explanation. Only a more critical study will resolve the point, but meanwhile in Glasgow T. McFadyen and A. Lyell ${ }^{3}$ have found a coagulase-positive staphylococcus in the blood of seven consecutive patients with generalized pustular psoriasis, and there was a good response to a six-week course of the appropriate antibiotic. They believe that deaths previously attributed to corticosteroids were more likely due to concealed bacteraemic shock. Yet the idea that pustular psoriasis can be caused by a bacteraemia is not easy to accept, because the pustules are sterile and the patients show no evidence of a pyaemia. McFayden and Lyell therefore suggest that pustular psoriasis is an "ide" eruption induced by the bacteraemia, though the "ide" is not the best of dermatological terms in that the firmness of its implicational overtones, so redolent of well-understood mechanisms, is out of all proportion to the flaccidity of definition.

The impontant practical conclusion is that bacteraemia should be looked for and treated appropriately in all patients with generalized pustular psoriasis, but until a bacteraemia is found and its response to antibiotics is confirmed there is a case for continuing to use methotrexate or corticosteroids when the patient's general condition and the severity of the rash warrant it.

1 Ryan, T. J., and Baker, British fournal of Dermatology, 1971, 85, 407. 2 Ryan, T. J., and Baker, H., British Fournal of Dermatology, 1969, 81, 134 3 McFayden, T., and Lyell, A., British fournal of Dermatology, 1971, 85, 274.

\section{Teaching Nutrition}

Nutrition is taught to medical students as fag-ends of physiology, biochemistry, clinical medicine, and paediatrics. This was borne out by a report on nutrition education in medical faculties received at last year's conference of the International Union of Nutritional Sciences. ${ }^{1}$ Prepared by a committee under the chairmanship of E. Kodicek, of the Dunn Nutritional Laboratory at Cambridge, the report recommended that professorial chairs and departments of nutrition should be established in medical schools, and it outlined a scheme for teaching the physiology, biochemistry, and pathology of nutrition and its effective application to community medicine and medical practice. It was proposed that the International Union of Nutritional Sciences should sponsor fellowships for students to train as medical nutritionists.

The report echoes criticisms that have been repeated over many years and which apply all over the world. ${ }^{2}$ The only professor of human nutrition in any British medical school has said ${ }^{3}$ that nutrition is neglected in our medical curriculum and that doctors are unable to interpret the results of recent advances in this branch of medical knowledge in a balanced and well-informed way. Proposals for teaching nutrition were made in evidence presented by the Nutrition Society ${ }^{4}$ to the Royal Commission on Medical Education, but they fell on stony ground, for the subject was not mentioned in the Todd report. 5

What is needed is a professor of nutrition in the medical school who can integrate teaching throughout the curriculum. A little progress has been made. In London there are now two higher degree courses leading to the M.Sc. in human nutrition, one in the Faculty of Medicine at the London School of Hygiene and Tropical Medicine, and the other in the Faculty of Science at Queen Elizabeth College. At Cambridge there is a postgraduate diploma course in nutrition, and nutrition is being introduced into a new pregraduate clinical course. Nutrition departments may soon be established in one or two undergraduate medical schools, and Nottingham already includes nutrition in its Bachelorship of Medical Science.

The day is past in Britain when Edward Mellanby could change the physique of the nation with some spoonfuls of cod-liver oil. We now have to learn the more subtle relationships that exist between nutrition and medicine, and how changes in food habits and changes in methods of food production may affect health. Medical education must keep pace with the rapid advances in this subject.

1 International Union of Nutritional Science, Proceeding of the Nutrition Society, 1971, 30, 191.

2 World Health Organization, Technical Report Series, 1971, 477, 78 3 Waterlow, J. C., Lancet, 1971, 2, 1196.

4 Nutrition Society, Proceedings of the Nutrition Society, 1967, 26, 141.

5 Royal Commission on Medical Education, 1965-8, Report, Cmnd. 3569. London, H.M.S.O., 1968. 